Hypothesis

\title{
The Hypercalcemic Effect of Vitamin D3 in Sarcoidosis Could Be a Side Effect of an Endogenous Program Organizing Cancer Apoptosis
}

\author{
Raimund von Helden ${ }^{1, *}$, William B. Grant ${ }^{2}$, Meis Moukayed ${ }^{3}$, Bernd Becker ${ }^{4}$ \\ 1 Institute VitaminDelta, Timmerschlade 14, 57368 Lennestadt; E-mail: raimund.vonhelden@t- \\ online.de \\ 2 Sunlight, Nutrition, and Health Research Center, PO Box 641603, San Francisco, CA 94164-1603, \\ USA; E-mail: wbgrant@infionline.net orcid.org/0000-0002-1439-3285 \\ 3 School of Arts and Sciences, American University in Dubai, UAE; PO Box 28282, Dubai, UAE; E- \\ mail: mmoukayed@hotmail.com \\ 4 MolCare Consulting, Schulsiedlung 6, D-93109 Wiesent; E-mail: bernd_becker@t-online.de \\ * Correspondence; E-Mail: Raimund.vonHelden@t-online.de; Fax: +49-3212-212-6600
}

\begin{abstract}
The cause of sarcoidosis is unknown, and vitamin D is contraindicated to treat the condition. We therefore ask what causes sarcoidosis and why vitamin $\mathrm{D}$ can be dangerous for those so afflicted. We propose a contrary hypothesis: sarcoidosis is a physiological process of defense against cancer that requires the substrate vitamin $\mathrm{D}$. We tested this hypothesis, finding many case reports involving sarcoidosis and cancer-further cases of cancer mimicry by sarcoidosis. Several reports describe spontaneous healing of cancer in the presence of sarcoidosis. In the context of the granulomas of sarcoidosis, monocytes are the site of vitamin D release. Furthermore, active vitamin D can control cancer cells by using the vitamin $\mathrm{D}$ receptors of the nucleus. That granulomas consistently do not caseate is explained as a confrontation with human molecules and the cancer cells' complete absorption. The striking fact that granulomas of sarcoidosis mostly lack cancerous cells is interpreted as a result of a well-functioning sarcoidosis process. We view the typical sarcoidosis monocytic synthesis of active vitamin D as a successful defense against cancer: a theory we call the "endogenous program organizing cancer apoptosis" (EPOCA).
\end{abstract}

Keywords: sarcoidosis; monocytes; cancer; neoplasia; vitamin D; 25-hydroxyvitamin D3; 1,25-hydroxyvitamin D3; etiology; spontaneous remission of cancer; vitamin D side effects 
Abbreviations and Terminology:

ACE: angiotensin-converting enzyme

EPOCA: endogenous program organizing cancer apoptosis

COSAC phenomenon: coincidence of sarcoidosis and cancer

Morbus Boeck: synonymous with sarcoidosis

etiology: synonymous with cause of disease

mimicry: imitation in biological image

passive vitamin D: 25-hydroxyvitamin D3, [25(OH)-vitamin D3]

active vitamin D: 1,25-dihydroxyvitamin D3, [1 $\alpha, 25(\mathrm{OH}) 2$-vitamin D3]

VDR: vitamin D receptor

\section{Background}

\subsection{History of Sarcoidosis}

One hundred twenty years ago, the dermatologist Peter Boeck described nodular changes of the skin in his publication "Multiple Benign Sarcoidosis" (

He interpreted these symptoms as a result of systemic disease. Since then, these changes in the skin have been called "sarcoidosis." Typically, sarcoidosis involves small bunches of cells that have been designated for the typical accumulation of granulocytes as a granuloma.

We found such clusters in different areas of the body, confirming the assumption of systemic disease. The original observations on the skin were raised, as the tip of an iceberg.

Today the cause of sarcoidosis remains unknown. Can this puzzle of medical science ever be resolved?

\subsection{Vitamin D and Sarcoidosis}

In the past decade, vitamin D has enjoyed increased attention. Monitoring vitamin D levels to help diagnose, prevent, and treat disease has increased enormously.

It is the task of science to identify the limits and possibilities of vitamin D. This leads to the question of toxicity and of an individual's elevated risk at a natural vitamin D level. Those who take vitamin $\mathrm{D}$ need to know whether any contraindication exists for using vitamin $\mathrm{D}$ in the range of physiological vitamin D levels. As such a contraindication to the use of vitamin D solely sarcoidosis is called. Can taking vitamin D induce side effects in the naturally achievable range of the vitamin D level? An unrecognized sarcoidosis should always be considered in such cases as the possible cause of adverse effects of vitamin D.

All users of vitamin D eventually come to this question: "What happens at the biochemical level if we give vitamin D in sarcoidosis?" This is a variation of the first question: "What causes sarcoidosis?"

At the end of this paper we propose a theory, endogenous program organizing cancer apoptosis (EPOCA), that strives to answer these questions. EPOCA postulates that sarcoidosis could be a beneficial physiological response. The availability of vitamin $\mathrm{D}$ in the body is the limiting factor of a useful defense reaction. Any observed side effect of administering vitamin D in a case of sarcoidosis would then merely indicate the start of a useful self-cleaning program. 


\section{Definition and Method}

EPOCA Theory (endogenous program organizing cancer apoptosis)

EPOCA consists of four principles:

1. Sarcoidosis is a physiological immune response that can always occur when malignant cells appear in the body.

2. Sarcoidosis can eliminate malignant cells and stop cancer at an early stage. The process is a spontaneous reaction that can protect the body from death by stopping the proliferation of malignant cells.

3. Sarcoidosis uses the active form of vitamin $\mathrm{D}$ to block the malignant cells biochemically and to destroy them by inducing apoptosis.

4. The availability of vitamin $\mathrm{D}$ is the limiting factor for this spontaneous defense against malignant processes.

Usually, EPOCA takes place unnoticed at the cellular level. If enough vitamin D is not available, a long-lasting dispute between malignant cells and monocytes will arise. In such a protracted struggle, this Process manifests macroscopically. Then sarcoidosis will be accompanied by the typical signs of the disease such as fatigue, fever, and the formation of larger granulomas. Step 1: 25-dihydroxyvitamin D3 must be present as a substrate for monocytes.

Figure 1 shows the principle of our EPOCA hypotheses in 4 steps:

Step 1: 25-dihydroxy-vitamin D3 must be present as a substrate for monocytes.

Step 2: Monocytes convert 25-vitamin-D3 into the active metabolite 1,25-dihydroxyvitamin D3. Step 3: Active 1,25-dihydroxy-vitamin D3 stops cellular proliferation via nuclear VDR target. Step 4: Monocytes recycling a neoplastic cell resulting in a quick disappearance. The steps 1, 2 and 3 represent the accepted knowledge of vitamin D, whereas step 4 represents our hypothesis. 


\section{Figure 1}

Physiology of sarcoidosis as hypothesized by EPOCA Monocytes activate vitamin D resulting in apoptosis of neoplastic cells.

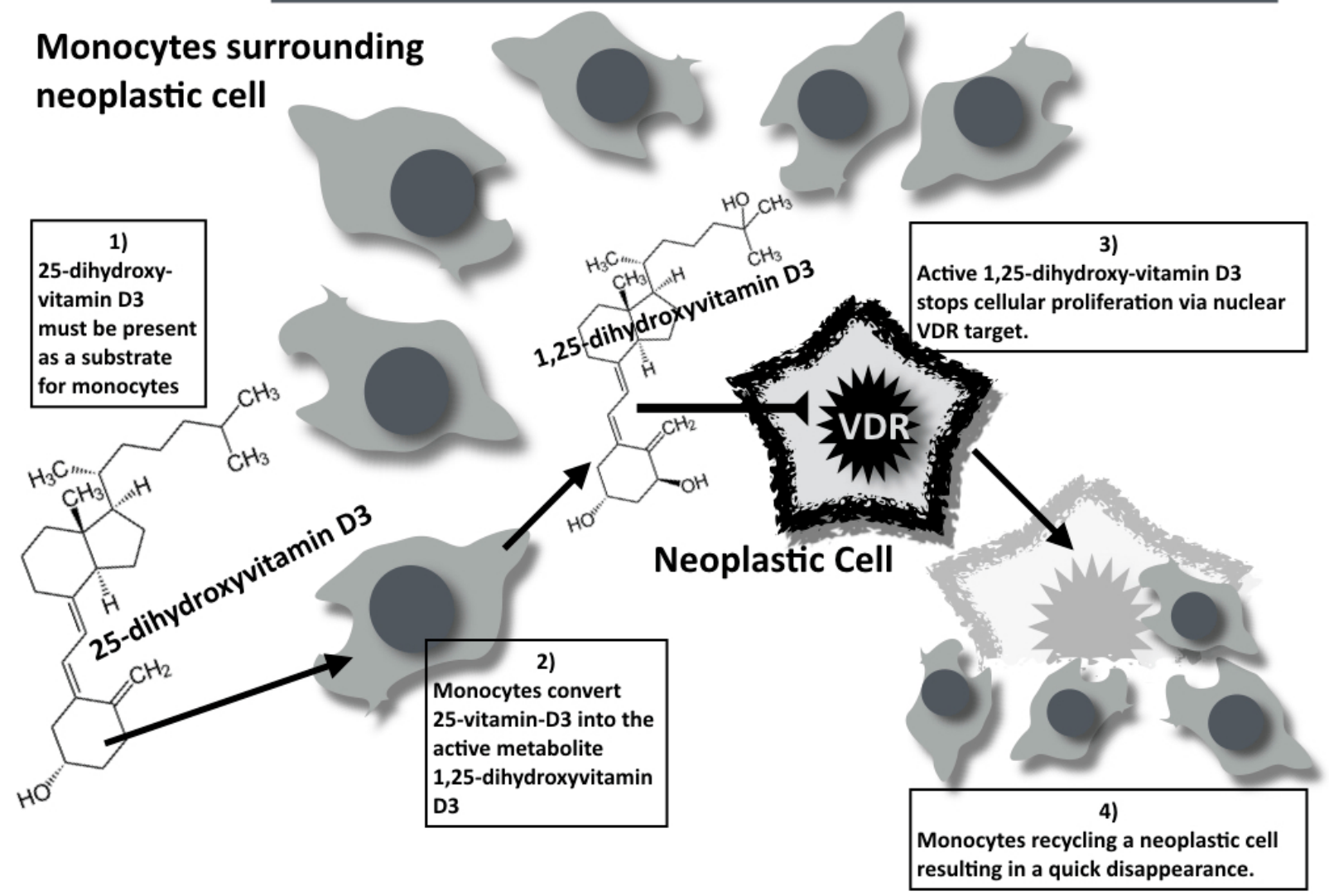

Falsification of EPOCA Theory

The following statements are plausible refutations of EPOCA, which therefore complement the preceding definition:

1. Sarcoidosis may arise even without the presence of faulty cells.

2. Sarcoidosis cannot protect against the spread of faulty cells in the body in most cases.

3. Sarcoidosis cannot inhibit and kill defective cells.

4. Administering vitamin $\mathrm{D}$ confers no advantage in inhibiting faulty cells in a case of sarcoidosis.

Point 4 of these principles involves a change of perspective. Treatment with vitamin $\mathrm{D}$ has been contraindicated for sarcoidosis. According to EPOCA theory, the only relevant contraindication for vitamin $\mathrm{D}$ will become an indication for vitamin D. A moderate and controlled application of vitamin $\mathrm{D}$ should therefore help in sarcoidosis.

\subsection{Method A: Coincidence of Cancer and Sarcoidosis}

EPOCA theory postulates that sarcoidosis is a biological defense against cancer. We must determine whether any clinical case reports describe patients in whom cancer and sarcoidosis were detected simultaneously. Such a scenario is a necessary condition for EPOCA theory. 


\subsection{Method B1: Spontaneous Remission of Cancer in Sarcoidosis}

EPOCA theory postulates that sarcoidosis is a biological defense against cancer. We must determine whether any clinical case reports describe patients in whom cancer, sarcoidosis, and spontaneous remission are observed simultaneously. Such a scenario would support EPOCA theory.

\subsubsection{Method B2: Sarcoidosis and Cancer in One Place}

EPOCA theory postulates that sarcoidosis is a biological defense against cancer. We must determine whether any clinical case reports describe patients in whom sarcoidosis and malignancy occur at one histological site. Such a scenario would support EPOCA theory.

\subsection{Method C: Epidemiological Phenomena of Sarcoidosis}

Does EPOCA theory explain all known epidemiological and clinical phenomena of sarcoidosis? What do we know about the characteristics of sarcoidosis?

A review of the medical literature yields the known properties of sarcoidosis. The phenomena described explain the object of EPOCA theory. The following are 12 epidemiological and clinical phenomena of sarcoidosis:

1. No carriers. All attempts to demonstrate microbial or viral pathogens as carriers were in vain $[1,2]$.

2. Worldwide spread. Sarcoidosis is common all over the world, with an estimated incidence of $1 \%$ of the population $[1,3]$.

3. All tissues affected. Sarcoidosis has been found in all organs. Even encapsulated tissue such as the brain $[4,5]$ and eyes $[6,7]$ may be affected.

4. Men younger than 40 and women older than 40 years. In men, sarcoidosis occurs more often in the first four decades of life. For ages over 40 years, however, more women are affected. Overall, the ratio between men and women is about 2:1.

5. Dark skin as a risk factor. The incidence of sarcoidosis in individuals with skin type 4-6 is 3.5 times greater than that for lighter skin types 1-3 [8-10]. The age-adjusted mortality was 12 times higher than in white people [11], and the radiographic stages of sarcoidosis were more advanced [12]. Also, a significant increase of mortality was reported for black females aged 55 years and older [13].

6. Age 30-40 years. The typical age for the development of sarcoidosis is between 30 and 40 years [14].

7. Northern latitude as a risk factor. Incidence of sarcoidosis is higher in the northern countries such as Iceland and Sweden $[15,16]$.

8. Spontaneous limitation by healing. A spontaneous remission has been described in $30 \%-70 \%$ of patients [2,17]. Judson reported that an anti-sarcoidosis treatment was not necessary in $39 \%$ of patients [12].

9. Low mortality (3\%). Only $3 \%$ of cases are fatal, although the disease can affect the whole body [17].

10. Noncaseating histology. Tuberculosis, for example, has the histological appearance of a caseating granuloma. A granuloma is a node of tissue with concentric shells of monocytes. In the histological center of tuberculosis always remains an amorphous substance that is not absorbed: "caseating granuloma." By contrast, the typical histological appearance of sarcoidosis is a "noncaseating granuloma" [1]. 
11. Cancer mimicry. In many case reports, biopsy of a supposedly typical macroscopic cancer process revealed the histological diagnosis of sarcoidosis. By this phenomenon, sarcoidosis mimics cancer[18].

12. Accompanying fatigue syndrome. Patients with diagnosed sarcoidosis often suffer from severe exhaustion, or fatigue. This typical phenomenon has been the subject of clinical trials, so far without success [19].

\subsection{Method D: Biochemistry of Sarcoidosis}

Does EPOCA theory explain the biochemical phenomena of sarcoidosis? A new theory must explain the observed biochemical phenomena plausibly. What do we know about the biochemical phenomena of sarcoidosis? Sarcoidosis has three major biochemical characteristics:

1. Active vitamin D. The macrophages localized in the granulomas of sarcoidosis autonomously produce the active form of vitamin D (1,25-dihydroxyvitamin D3). The active form of vitamin $\mathrm{D}$ in the blood can lead to hypocalcemia and hypercalciuria [20]. This was why vitamin D was contraindicated for sarcoidosis.

2. Effect of cortisone therapy. Even a low-dose therapy with cortisone can cause regression of sarcoidosis [21].

3. Serum angiotensin-converting enzyme (ACE) as a marker. An elevated serum level of ACE protein is characteristic for acute sarcoidosis. After regression of sarcoidosis, ACE levels drop to normal [22]. ACE can raise blood pressure [23].

\section{Results}

Examination of EPOCA theory with the described Methods A-D

\subsection{Method A: Coincidence of Cancer and Sarcoidosis}

How often does sarcoidosis occur with cancer?

EPOCA theorizes that sarcoidosis is a biological response to neoplastic tissue. A frequent coincidence would support the theory.

We searched the National Library of Medicine's PubMed database (pubmed.gov) with the following keywords: "neoplasia \& sarcoidosis \& case report". We found 1244 hits, accounting for $14.3 \%$ of 8670 entries, of case reports found by the search term "sarcoidosis \& case reports". This means that approximately every seventh report shows the coincidence of cancer and sarcoidosis. The large number of case reports is an independent medical phenomenon that we call coincidence of sarcoidosis and cancer (COSAC).

\subsubsection{Method B: Spontaneous Remission of Cancer in Sarcoidosis}

EPOCA theory postulates a defense against cancer by sarcoidosis. Do any reports describe a spontaneous remission of malignant disease in the presence of sarcoidosis? We searched PubMed with the following keywords: "neoplasia \& spontaneous sarcoidosis remission \& case report". This search yielded 12 publications:

1. Cutaneous sarcoidosis response in a patient with bladder cancer [24]

2. Two cases of sarcoidosis-lymphoma syndrome [25]

3. Spontaneous resolution of a multiorgan sarcoidosis with malignant lymphoma [26] 
4. Coincidence of seminoma and sarcoidosis: A myth or fact? [27]

5. Pseudo-sarcoidotic lymphoma and nephrotic syndrome in a hepatitis $\mathrm{C}$-carrying female patient [28]

6. Spontaneous regression of granulomatous mycosis fungoides in an HIV-positive patient [29]

7. Bone lesions mimicking disseminated malignancy after remission of thoracic sarcoidosis [30]

8. Recurrence of sarcoidosis stage I after recovery [31]

9. Spontaneous regression of bilateral hilar lymphadenopathy in renal cell carcinoma [32]

10. Fatal clinical outcome in a patient with sarcoidosis-lymphoma syndrome [33]

11. Case records of the Massachusetts General Hospital. Case 4-2014. A 39-year-old man with night sweats and abdominal pain [34]

12. Coexistence of mediastinal adenopathies of different etiologies - case report [35]

13. Most of those described spontaneous remission in coincidence of a malignant disease with sarcoidosis $(1-4,7,9,10,12)$. We address three of those cases here.

\section{Literature Case Report 1}

COSAC phenomenon: Bladder transitional cell carcinoma

A 60 -year-old woman had rashes on her forehead. Eight months earlier the diagnosis of bladder cell carcinoma was confirmed. By histology, the skin rashes were proven sarcoidosis granulomas.

The patient was further treated with radiation and chemotherapy of bladder cancer. No changes of skin symptoms were evident during conservative therapy. Since the conservative therapy for bladder cancer did not succeed, surgery took place. Seven months after surgery sarcoidosis plaques disappeared [24].

From the perspective of EPOCA theory, this case report is a typical example of the COSAC phenomenon. The simultaneous occurrence of carcinoma and sarcoidosis is a condition for EPOCA theory. Sarcoidosis may be interpreted in this case report as a successful therapy support.

\section{Literature Case Report 2}

COSAC phenomenon: Seminoma

Another case report describes the occurrence of sarcoidosis during successful chemotherapy for seminoma. The authors assume that the breakdown of tumor cells induced by chemotherapy might cause the noncaseating granulomas during treatment. Noncaseating granulomas are typical of sarcoidosis [36].

From the perspective of EPOCA theory, tumor cells have been inhibited by sarcoidosis, which typically shows noncaseating granulomas.

\section{Literature Case Report 3}

COSAC phenomenon: Gingival cancer

A typical sign of sarcoidosis is an increase in serum ACE level. Hanibuchi and colleagues describe a patient with gingival carcinoma occurring with sarcoidosis [16]. The diagnosis of sarcoidosis was based on $\mathrm{CD}^{+}$lymphocytes from bronchoalveolar lavage and noncaseating granulomas in the transbronchial lung biopsy. Serum level of ACE increased. The patient was treated with low-dose prednisolone (30 mg daily). Serum ACE decreased to normal levels, which was evaluated as a success [37].

From the viewpoint of EPOCA theory: Carcinoma and sarcoidosis were observed together. The coincidence was not accidental because sarcoidosis followed the cancer. Both diseases decreased in 
parallel, because sarcoidosis deleted the cancer cells. This phenomenon and the complete response support EPOCA theory.

\subsection{Method C: EPOCA Theory and Known Phenomena of Sarcoidosis}

Does a plausible explanation exist for the phenomena of sarcoidosis? We tried to use EPOCA theory to explain all 12 phenomena of sarcoidosis:

1. No carriers. EPOCA theory requires no external organisms or vectors of transmission, because it postulates an endogenous process. This assertion explains why all tests failed to detect pathogens as carriers.

2. Worldwide distribution. The global distribution of sarcoidosis can be explained by the worldwide spread of cancer.

3. All tissues. Because all tissues can develop cancer, the EPOCA phenomenon can also occur anywhere in the body.

4. Young men, older women. Many men younger than 40 years have particularly low vitamin D levels. Therefore, the EPOCA reaction is slower and less effective in a vitamin D-deficient man. In this way, more cases of sarcoidosis appear macroscopically. Many women older than 40 years have a vitamin D deficiency. Many women in this age group avoid direct sunlight and use cosmetics for sun protection. The EPOCA reaction is inefficient in women over 40 because vitamin $\mathrm{D}$, as the substrate for an efficient and short EPOCA reaction, is lacking, leading to more cases of sarcoidosis.

5. Dark skin as a risk factor. People with dark skin in the northern latitudes have lower vitamin D levels. Therefore, the EPOCA reaction remains without adequate substrate and runs inefficiently and needs a long time to complete.

6. No incidence with age over 70 years. Vitamin D synthesis decreases with age. If someone older than 70 years experiences malignant cell growth, the EPOCA reaction can fail, increasing cancer mortality.

7. Northern latitude as a risk factor. Normally the endogenous EPOCA reaction starts at the cellular level, not appearing macroscopically. The higher incidence of sarcoidosis in northern countries occurs because of a long-lasting vitamin D deficiency, which delays the EPOCA reaction.

8. Spontaneous limitation by healing. A spontaneous healing is the physiological target of the EPOCA reaction. When this task is fulfilled, the program will self-terminate. The well-known spontaneous remission in many sarcoidosis cases points to the high efficiency of the program.

9. Low mortality (3\%). Untreated cancer has a high mortality rate. The particularly low $3 \%$ mortality rate of sarcoidosis shows the high efficiency of the EPOCA process.

10. Noncaseating granulomas. Tuberculosis forms "caseating" granulomas. We assume that it is because the bacterial proteins are recognized as foreign and therefore cannot be recycled. By contrast, sarcoidosis granulomas are "noncaseating" because all structures in the center of the granuloma derived from the body's own cells. These fragments of malignant cells in the center of sarcoidosis can be recycled completely. This explains why noncaseation is the classic histologic hallmark of any sarcoidosis.

11. Cancer mimicry. When neoplastic cells are spreading, the EPOCA response is needed to control these altered cells. The monocytes, surrounding the altered cells, have to enclose the diseased tissue in several layers. Sarcoidosis thus overlies existing cancer tissue. After the elimination of cancer cells, remaining macroscopically visible structures are identified as cancer mimicry. In cases where malignant cells are still detectable, this phenomenon reflects the COSAC phenomenon. This phenomenon in turn is a consequence of the EPOCA process.

12. Fatigue. When a patient suffers from a serious and persistent fatigue, the physician must either find neoplastic disease or exclude it as a cause. EPOCA theory also assumes that during sarcoidosis uncontrolled cell growth accounts for the exhaustion. Prolonged vitamin D 
deficiency can be a second cause of fatigue in sarcoidosis. Sarcoidosis is almost always coupled with vitamin D deficiency for a reason: A sarcoidosis is macroscopically evident only when vitamin $\mathrm{D}$ is lacking. Otherwise, the problem would have been solved at the microscopic level. EPOCA theory interprets the long course of sarcoidosis as a result of persistent vitamin $\mathrm{D}$ deficiency. The association between vitamin $\mathrm{D}$ deficiency and fatigue is known in the literature as the acute syndrome of vitamin D deficiency. The proof of principle is provided by restoring normal vitamin D levels [38]. Vitamin D deficiency in sarcoidosis doubles the disadvantage: on one hand, the deficiency is responsible for the protracted course of sarcoidosis; on the other hand, fatigue - the typical sign of the acute syndrome of vitamin D deficiency - is more intense.

EPOCA theory suitably accounts for all 12 phenomena of sarcoidosis.

\subsection{Method D: EPOCA Theory and the Biochemistry of Sarcoidosis}

The following biochemical phenomena of sarcoidosis serve to check EPOCA theory:

1. Active vitamin $\mathrm{D}$. The release of active vitamin $\mathrm{D}, 1,25$-dihydroxyvitamin $\mathrm{D} 3$, by monocytes involved in granuloma suppresses harmful activities of neoplastic cells.

2. Effect of cortisone. High serum levels of cortisone suppress intestinal absorption of calcium. In the next step, a low level of serum calcium causes a physiological counter regulation of calcium homeostasis. Parathyroid hormone transforms passive vitamin D into active vitamin D. With reduced intestinal calcium absorption, the organism the organism has to increase this loop of activation. Therefore cortisone application results in an increased presence of active vitamin D. High levels of active vitamin D inhibit proliferation of neoplastic cells. In the context of EPOCA theory, administering cortisone supports the monocytes in their fight against neoplastic cells by increasing levels of active vitamin D. However, administering cortisone may not work if vitamin D is lacking. Whenever cortisone fails to treat sarcoidosis, low vitamin D levels may be the cause.

3. High levels of serum ACE. High ACE serum level is an accepted parameter for the activity of sarcoidosis. The body releases ACE in response to low blood pressure. The EPOCA process typically lowers blood pressure because the granuloma-forming monocytes produce large amounts of 1,25-dihydroxyvitamin D3. Thus, a high serum ACE level is the physiological consequence of elevated levels of active vitamin D. Confirmation of this view can be confirmed or refuted by the simultaneous determination of ACE and VDX: The serum level of $\mathrm{ACE}$ is understood as a cheap indicator for the level of active vitamin D.

\section{Discussion}

In recent years, vitamin D research has dealt extensively with the effects of the hormonal vitamin D system in various diseases. Vitamin D has increasingly been found advantageous, whereas adverse effects at a natural vitamin $\mathrm{D}$ level could be excluded. The only exception to this rule so far has been the sarcoidosis disease. This condition is due to hypocalcaemia, resulting from high levels of active vitamin D. That is why vitamin D supplementation is contraindicated for sarcoidosis. This exception raises the old question of what occurs with sarcoidosis.

Whenever a scientific concept encounters an exception to the rule, we must find the reason. Albert Einstein could not accept that he would not see his face in a mirror moving at the speed of light. So he set out to change our perception of space and time. Does the exception for treatment with vitamin D open the door to a new system of understanding? This constellation of "rule and exception" could contain special information for how we perceive both sarcoidosis and vitamin D. 
Therefore, we discuss the inverted perception, whether sarcoidosis may be useful for the organism and vitamin D could be helpful as well. If so, vitamin D could be applied with the intention to cure sarcoidosis. A physiological level of vitamin D could be of great value, because an inborn cellular program could destroy cancer cells much sooner in the course of disease.

\subsection{The Unresolved Medical Issue}

Sarcoidosis has been seen as a granuloma-forming disease of unknown cause. However, the triggering factor is unclear. A recent report of efforts to discover the etiology of sarcoidosis ends with the words "What is the cause of sarcoidosis?" [39].

\subsection{Review}

Infection

Some epidemiological data suggest an infectious etiology: activated macrophages can be detected in cells from bronchial lavage. In a normal immune response, infection activates these cells [40].

Toxins

Rose and colleagues observed that the bacterial toxins in aerosols resulted in granulomatous lung diseases [41].

\section{Bacterial or Viral Causes}

Although bacterial infection and sarcoidosis occasionally occur together, not a single microbial cause could be reproducibly defined. The PCR analysis confirmed that no evidence existed for a viral trigger [42].

Metal

Inhaling inorganic substances can induce sarcoidosis, as Rafnsson and colleagues reported [43] Exposure to metals such as beryllium, titanium, aluminum, and zirconium is discussed as a trigger for sarcoidosis. The penetrance of risk is governed by two factors: genetic background and intensity of exposure [44-48].

\section{Cancer and Sarcoidosis: An Unresolved Tension}

The relationship between cancer and sarcoidosis has been explored by Safianowska and colleagues [49] and Dabrowska and colleagues [50]. Researchers led by Brinckerhoff, Alexandrescu, Caras, and Cohen showed the close relationship between sarcoidosis and various malignancies [51-54]. Bonifazi calculated the relative risk of cancer in a case of sarcoidosis as 1.19 RR [55].

However, no authors considered that sarcoidosis might be a physiological process. The statistical linkage between sarcoidosis and malignancy was tested and rejected by Seersholm and Ungprasert and their respective colleagues, because no increased risk was evident during observation [56,57].

Even so, such an approach cannot disprove EPOCA theory because EPOCA theory is not about a serial time sequence of the two diseases, but rather their simultaneous appearance. The authors illustrated the statistical fact that no increased risk of malignancy was evident in the "further course." However, revealing the high protective power of sarcoidosis against cancer confirms the protective power of the EPOCA phenomenon. The contradiction between the authors' opinion of elevated and normal risk can be explained if one considers the risk table of Bonifazi [55]. In the first 4 years after the 
diagnosis of sarcoidosis, the relative risk (RR) for a discovery of cancer cells with 1.41 is the highest. Over the next 5 years, it drops to $1.31 \mathrm{RR}$. After more than 10 years, it is only 1:06 RR. Obviously, at an early stage cancer can still be detected, while the cancer cells are already resolved at a later time. For this explanation, EPOCA theory is supported by the analysis of various cancers. Cancers that are detected by a simple routine diagnostic in an early stage, such as skin cancer, leukemia, and Hodgkin's disease have a higher relative risk of coincidence of greater than 2.0 RR. EPOCA theory postulates that a slight diagnostic access meets an early stage of the EPOCA process and succeeds in showing remaining malignant cells. Also, a cancer site that is difficult to access, such as pancreatic or prostate cancer, will not show malignant cells anymore: the relative risk for a coincidence drops to $1.1 \mathrm{RR}$.

\section{Coincidence}

More than 1000 case reports of coincident sarcoidosis and cancer (COSAC) reported in PubMed clearly indicate a structural relationship between the diseases. Another simple search of that database showed that every seventh sarcoidosis case report describes the coincidence of sarcoidosis with malignant disease. Even if these numbers are not statistically valid, the high numbers emphasize that a connection might exist.

\section{Mimicry as a Key}

EPOCA theory assumes that when sarcoidosis and cancer are both present, sarcoidosis can overcome the malignant cells. Histologically, the malignant cells would disappear and only the macroscopic structures of a locally invasive and metastatic cancer disease would remain. Our database research showed that such cases are described. These case reports appear in the medical literature as cancer mimicry by sarcoidosis granuloma. This "happy failed diagnosis" is always very impressive for treating physicians: The supposedly accurate diagnosis of cancer is revealed histologically as the harmless disease of sarcoidosis. Many reports of this phenomenon of mimicry exist. We call this phenomenon sarcoidosis mimicking malignant disease. Searching with the keyword string "sarcoidosis \& mimicking \& neoplasia \& case report" yielded 109 results. We present 89 of them with a typical story of mimicking. This collection further confirms EPOCA theory [30,58-145].

\section{Biochemistry of Cancer Defense}

The Phenomenon of Vitamin D Activation

Patients with sarcoidosis present with higher serum levels of active vitamin D (1,25dihydroxyvitamin D3) than healthy control subjects [146]. This phenomenon sometimes is accompanied by dangerous hypercalcemia [146]. Could this scenario be an advantage for the patient "suffering from sarcoidosis"?

Epidemiology

Epidemiological studies of Garland and Gorham and their colleagues support these findings at the molecular level. The presence of 1,25-dihydroxyvitamin D3 can reduce the risk of breast or colon cancer $[147,148]$. Is this active form of vitamin D detectable in the cells of sarcoidosis?

\section{Detecting Active Vitamin D}

Adams and colleagues examined primary cultures of pulmonary alveolar macrophages. The researchers confirmed that granulomatous cell clusters of sarcoidosis produce 1,25-dihydroxyvitamin 
D3 [20,149]. Characteristic for sarcoidosis is the increase in macrophage activity in the granulation tissue. The macrophage activity increases synthesis of 1,25-dihydroxyvitamin D3 [150-152]. Are the monocytes responsible?

Monocyte Power

Monocytes are the only known cell type releasing active vitamin D, 1,25-dihydroxyvitamin D3, in such high concentrations that a biochemical blockade of DNA replication occurs in neoplastic cells [153]. The uniquely high levels of active vitamin D in sarcoidosis tissue lead to EPOCA theory's assumption of a natural process of production. Is this production correct localized?

Location

The concentrated activity of monocytes gathered in precisely these areas may represent useful purpose [154-156]. What exactly is the function of active vitamin D?

Effect

According to EPOCA theory, active vitamin D (1,25-dihydroxyvitamin D3) acts as a natural molecule of defense against cancer and inhibits the development of early stages of malignant cells on the path of transformation to malignancy. What happens at the genetic level?

Defense against Cancer by Gene Regulation

The defense reaction takes place by a genomic effect. Through the vitamin D receptor (VDR), active vitamin $\mathrm{D}$ affects the expression of proliferation genes, thereby suppressing growth and metastasis. Finally, active vitamin D upregulates those genes that trigger apoptosis and autophagy $[155,157,158]$. Can active vitamin D stop malignant cells?

Active Vitamin D and Cancer

Furthermore, 1,25-dihydroxyvitamin D3 selectively regulates cell proliferation, inducing cell cycle arrest and apoptosis in malignant cells. Active vitamin D suppresses cell adhesion molecules and growth factors that may promote metastasis. These effects are mediated by active vitamin D's genomic effect via the nuclear VDR. These receptors are present on many cells of the body. Moreover, active vitamin D can modulate the immune reaction of immune cells. It is believed that it potentiates the response of the innate immune system. Active vitamin D also regulates cancer-associated autophagy, which is important in preventing tumor growth in vivo [54]. Moukayed and Grant recently showed these mechanisms linking 1,25-dihydroxyvitamin D3 and cancer prevention [157,158]. Are these processes detectable at the cellular location of sarcoidosis?

System Monitoring

Together with the fact that the nuclear receptors are expressed for 1,25-dihydroxyvitamin D3 in many cells of the human body [159], we postulate that the synthesis of 1,25-dihydroxyvitamin D3 is a mechanism of self-defense. It is used in all tissues of the body, to protect against emerging cancer cells or metastases. Do we have to reassess sarcoidosis? 
No fail of nature

From the EPOCA point of view, the synthesis of 1,25-dihydroxyvitamin D3 by macrophages in sarcoidosis tissue is no fail of nature. Rather, it is a useful program to defend against cell transformation in these places. Can we use animal models to confirm this assertion?

Cellular biochemistry of active vitamin D

Evidence from in vitro studies and in vivo animal models shows that 1,25-dihydroxyvitamin D3 blocks cellular transformation and protects against metastasis in cancer $[160,161]$.

\subsection{Paradigm shift}

Why have cancer cells not yet been recognized as a cause of sarcoidosis? Only a short acquisition time exists from malignant transformation to sarcoidosis reaction. EPOCA theory assumes that malignant cells already have killed, dissolved, and removed these sarcoid cells without any residues. This effectiveness has led to a fundamental misunderstanding of sarcoidosis as a disease. How could this misinterpretation persist for more than 100 years?

Conflated Cause and Effect

Imagine this scene from everyday life: Arriving at a street crossing, you find it blocked with more than 100 police officers. You start to become impatient. Later, you report that "police hindered the traffic." That the presence of many police officers resulted in the arrest of many criminals is not apparent to you. You could even make a further mistake, concluding that too many police officers are working in the city. Finally, you could argue to reduce these police forces. This scenario describes the widespread fallacy of medical science's conventional approach to sarcoidosis.

EPOCA: Physiological rather than Pathological

EPOCA theory is opening the gateway to a paradigm shift. Sarcoidosis is no longer a "dysfunction" of monocytes, but rather a desirable healthy reaction against the proliferation of tumor cells. Sarcoidosis has been classified as a disease because the EPOCA mechanism was not recognized.

Sarcoidosis as a Sign of Healing

The view that sarcoidosis indicates healing is supported by a recent case-control study of Steinfort and colleagues. In patients with lung cancer treated by surgical resection, sarcoidosis tissue was detected in local lymph nodes in association with a lower rate of cancer recurrence [162]. EPOCA theory explains the synthesis of 1,25-dihydroxyvitamin D3 in sarcoidosis granulomas an endogenous chemotherapy against the development of tumor cells.

Fall of the Last Contraindication for Vitamin D

Confirming EPOCA theory would mean that the use of vitamin D loses its last and only contraindication. Instead, vitamin D could be allowed for treating sarcoidosis by gradual application. However, the risk of hypercalcemia should be monitored in any case. This risk was explored in a randomized controlled trial with 250,000 IU of vitamin D resulting in a rise of the mean vitamin D level and one case of hypercalcemia in 13 cases (7\%) [163]. Bolland concluded "little indication" for vitamin D in a case of sarcoidosis; however, the effect on the course of sarcoidosis was not reported. Kamphuis concluded that vitamin D should be supplemented in case of deficiency [164]. Indeed, reports exist in which applying vitamin $\mathrm{D}$ showed an unexpected improvement over many months of ending 
sarcoidosis. Even cases of successful tumor regression after vitamin D application have been reported [165].

Novel Cancer Therapy

The regression of cancer caused by the release of 1,25-dihydroxyvitamin D3 could lead to a new class of cancer therapies. The target is to provoke a sarcoidosis response against a malignant process. This approach probably represents one of the most effective therapeutic options because it uses an existing biological system. Vitamin D is the key for starting this system of EPOCA.

\section{Novel Cancer Prevention}

Vitamin D deficiency is associated with increased mortality in Germany. We calculated an associated mortality rate of 18,000 lives lost each year [166]. The EPOCA theory submitted here is one causal explanation for this large number. Without enough vitamin $\mathrm{D}$, the substrate for the blockade of cancer cells is lacking. Therefore, administering vitamin $\mathrm{D}$ can be regarded as an effective measure to prevent cancer.

\section{Mental Obstacles to EPOCA Theory}

The essential ideas of EPOCA theory were presented at the 4TH INTERNATIONAL SYMPOSIUM ON VITAMIN D AND ANALOGS IN CANCER PREVENTION AND THERAPY in Homburg (Saar) in 2011 [18]. Another presentation followed on the Vitamin D Update 2013 congress in Berlin [165,167]. The EPOCA hypothesis concerns several practice areas of medicine. The first area is pulmonology, whose practitioners treat sarcoidosis patients. We must also consider the oncologists who diagnose and treat cancer. The third area covers the vitamin D researchers who investigate the relationship between vitamin $\mathrm{D}$ and cancer defense.

Even in modern science new findings can remain hidden for a long time because they arouse negative emotions. Having researchers leave their traditional working area and invade neighboring areas can be burdensome. Therefore, the interdisciplinary perspective of EPOCA theory involves additional stress for those who deal with it. Everyone is inclined to quickly retreat to his own comfortable territory: it is difficult to publish scientific statements concerning a neighboring area.

A second stress arises, through a problematic change in the patient's perspective. When the EPOCA theory is presented to sarcoidosis patients, they face the idea of uncontrolled cell proliferation: "Cancer" causes the sarcoidosis symptoms. This new perspective is not trivial. The physician should moderate the psychological stress for the patient with facts. First, the prognosis of sarcoidosis with 97\% healing is an excellent response. According to EPOCA theory, this observed reaction is a reliable physiological work. It is a psychological advantage of EPOCA theory that it eliminates the anxiety over a mysterious disease. The result of this talk is a prospect of a cure in the near future. It is most important that this understanding give a new and successful approach to therapy.

So far, the therapeutic success with the preferred cortisone therapy has been inconsistent. The reason for this is attributed to the lack of perception of vitamin D levels. In EPOCA theory, vitamin D is an essential component of healing and shortening the course of sarcoidosis. 
Even if the sarcoidosis patient is confronted with the idea of a malignant disease, it is helpful to know that the cause of this disease is clarified and that a manageable solution to the chronic course exists. How could a doctor communicate the confirmed diagnosis of sarcoidosis? We compiled our ideas in the following draft touching all four important aspects.

\section{How to Communicate the EPOCA Diagnosis to the Patient?}

Imagine that there is a physiological response to a disease!"

1. "I have good news about your health. Your body is showing the symptoms of a so-called sarcoidosis. By reacting this way, your body has proven that it is strong enough to recognize a potential danger and to fight with its natural defenses."

There is a known cause.

2. "This disease is characterized by the presence of precursors of a disease characterized by the abnormal growth of cells. Sarcoidosis keeps these cells from proliferating and harming you." There is a good prognosis.

3. "The defense of the body is strong enough to overcome these defective cells in $97 \%$ of cases."

There is an efficient therapeutic support.

4. "In this defense of the faulty cells, the body needs the right amount of vitamin D—not too little and not too much. With vitamin D the body is supported and the time of curing is shortened. Treatment with vitamin D results in a further increase of the mentioned success rate of $97 \%$."

Our discussion of EPOCA therapy shows the biochemical relationships between the disciplines. EPOCA theory is a plausible explanation for all the features of sarcoidosis. With a readily available substance such as vitamin d physicians may assist the physiological process. We see the beginning of a new field of oncological research with the task of initiating the EPOCA reaction after cancer diagnosis.

\section{Conclusions}

EPOCA theory sees sarcoidosis as a physiological response to cells with unphysiological growth. This are the four items of this hypothesis:

A) Case reports of coincidence of neoplasms in connection to sarcoidosis amount to $14 \%$ of all case reports of sarcoidosis and underline the connection. The known mimicry of cancerous structures by sarcoidosis could be due to the successful overlay of existing cancer cells.

B) All known phenomena of sarcoidosis were reviewed and can be explained in the new context: The pathognomonic "lack of caseation" in the histological picture is based on the full absorption of the body's own material. The pattern of the epidemiologic spread of sarcoidosis corresponds to the distribution of the vitamin D deficiency. In the absence of vitamin D the physiological process of sarcoidosis is weaker, longer and more evident to the eye of the doctor.

C) The biochemical forces of active vitamin D are suitable to inhibit growth. Monocytes releasing active vitamin $\mathrm{D}$ can induce apoptosis of malignant cells.

D) There could be a shift in the understanding of an uncategorized medical phenomenon: Sarcoidosis is no longer a pathological but a physiological response. This changes a basic medical paradigm: The patient's sarcoidosis was a contraindication for application of vitamin $\mathrm{D}$. This paradigm changes to an indication for vitamin D. Vitamin D however should be applied cautiously under control of serum creatinine and serum calcium levels. Furthermore a new class of cancer therapy might arise 
from the concept of sarcoidosis as a helpful process when a cancer disease is present. For existing sarcoidosis, one can expect a shorter course of disease.

If confirmed, EPOCA theory would justify an uninterrupted supply of vitamin D to prevent cancer. In all countries whose populations lack vitamin $\mathrm{D}$, appropriate structures should be created to allow people to monitor their own vitamin D levels. In case of deficiency, a suitable substitution should be managed.

Further studies with the aim of a curative application of vitamin D for sarcoidosis are suggested under four conditions:

1) A continuous weekly monitoring of calcium and creatinine and

2) A medication of $5 \mathrm{mg}$ of Prednisolone for the phase of elevated serum-ACE

3) The physician's consciousness for the coincidence of sarcoidosis and neoplasia

4) A careful titration of vitamin D3 especially in the ascent from 10 to $20 \mathrm{ng} / \mathrm{ml}$

\section{Conflicts of Interest}

WBG receives funding from Bio-Tech Pharmacal (Fayetteville, AR) and the Vitamin D Council (San Luis Obispo, CA). The other authors declare no conflict of interest.

\section{References}

1. Iannuzzi, M.C.; Rybicki, B.A.; Teirstein, A.S. Sarcoidosis. The New England journal of medicine 2007, 357, 2153-2165.

2. Nunes, H.; Bouvry, D.; Soler, P.; Valeyre, D. Sarcoidosis. Orphanet journal of rare diseases 2007, 2, 46.

3. Rybicki, B.A.; Major, M.; Popovich, J., Jr.; Maliarik, M.J.; Iannuzzi, M.C. Racial differences in sarcoidosis incidence: A 5-year study in a health maintenance organization. American journal of epidemiology 1997, 145, 234-241.

4. Grand, S.; Hoffmann, D.; Bost, F.; Francois-Joubert, A.; Pasquier, B.; Le Bas, J.F. Case report: Pseudotumoral brain lesion as the presenting feature of sarcoidosis. The British journal of radiology 1996, 69, 272-275.

5. McCartney, W.H.; Lindner, L.E.; Prather, J.L.; Nusynowitz, M.L. Brain scan abnormalities in intracerebral sarcoidosis. Clinical nuclear medicine 1979, 4, 32-34.

6. Badelon, I.; Chaine, G. [eye manifestations of sarcoidosis]. La Revue du praticien 1994, 44, 20422045.

7. Cross, A.G. Sarcoidosis of the eye. The British journal of ophthalmology 1953, 37, 247-250.

8. Cozier, Y.C.; Berman, J.S.; Palmer, J.R.; Boggs, D.A.; Serlin, D.M.; Rosenberg, L. Sarcoidosis in black women in the united states: Data from the black women's health study. Chest 2011, 139, 144-150.

9. Heath, C.R.; David, J.; Taylor, S.C. Sarcoidosis: Are there differences in your skin of color patients? J Am Acad Dermatol 2012, 66, 121 e121-114.

10. Keller, A.Z. Hospital, age, racial, occupational, geographical, clinical and survivorship characteristics in the epidemiology of sarcoidosis. American journal of epidemiology 1971, 94, 222-230. 
11. Mirsaeidi, M.; Machado, R.F.; Schraufnagel, D.; Sweiss, N.J.; Baughman, R.P. Racial difference in sarcoidosis mortality in the united states. Chest 2015, 147, 438-449.

12. Judson, M.A.; Boan, A.D.; Lackland, D.T. The clinical course of sarcoidosis: Presentation, diagnosis, and treatment in a large white and black cohort in the united states. Sarcoidosis Vasc Diffuse Lung Dis 2012, 29, 119-127.

13. Swigris, J.J.; Olson, A.L.; Huie, T.J.; Fernandez-Perez, E.R.; Solomon, J.; Sprunger, D.; Brown, K.K. Sarcoidosis-related mortality in the united states from 1988 to 2007. Am J Respir Crit Care Med 2011, 183, 1524-1530.

14. Hillerdal, G.; Nou, E.; Osterman, K.; Schmekel, B. Sarcoidosis: Epidemiology and prognosis. A 15-year european study. The American review of respiratory disease 1984, 130, 29-32.

15. Milman, N.; Selroos, O. Pulmonary sarcoidosis in the nordic countries 1950-1982. Ii. Course and prognosis. Sarcoidosis 1990, 7, 113-118.

16. Siltzbach, L.E.; James, D.G.; Neville, E.; Turiaf, J.; Battesti, J.P.; Sharma, O.P.; Hosoda, Y.; Mikami, R.; Odaka, M. Course and prognosis of sarcoidosis around the world. The American journal of medicine 1974, 57, 847-852.

17. Statement_on_sarcoidosis. Statement on sarcoidosis. Joint statement of the american thoracic society (ats), the european respiratory society (ers) and the world association of sarcoidosis and other granulomatous disorders (wasog) adopted by the ats board of directors and by the ers executive committee, february 1999. Am J Respir Crit Care Med 1999, 160, 736-755.

18. Von Helden, R. Numerous cases of sarcoidosis masquerading neoplasia: By chance or by etiological association? Anticancer research 2011, 31, 1489-1512.

19. De Vries, J.; Lower, E.E.; Drent, M. Quality of life in sarcoidosis: Assessment and management. Semin Respir Crit Care Med 2010, 31, 485-493.

20. Adams, J.S.; Sharma, O.P.; Gacad, M.A.; Singer, F.R. Metabolism of 25-hydroxyvitamin d3 by cultured pulmonary alveolar macrophages in sarcoidosis. The Journal of clinical investigation 1983, 72, 1856-1860.

21. Hanibuchi, M.; Matsumori, Y.; Nishioka, Y.; Sone, S. A case of sarcoidosis accompanying squamous cell carcinoma in the mandibular gingiva. The journal of medical investigation : JMI 2005, 52, 118-121.

22. Lieberman, J. Elevation of serum angiotensin-converting-enzyme (ace) level in sarcoidosis. The American journal of medicine 1975, 59, 365-372.

23. Dupont, M.; Jover, B.; Mialanes, N.; Mimran, A. [clinical value of the estimation of plasma converting enzyme activity]. Pathologie-biologie 1984, 32, 698-701.

24. Yukawa, M.; Satoh, T.; Takayama, K.; Yokozeki, H. Cutaneous sarcoid reaction in a patient with bladder cancer. Eur J Dermatol 2010, 20, 235.

25. Suvajdzic, N.; Milenkovic, B.; Perunicic, M.; Stojsic, J.; Jankovic, S. Two cases of sarcoidosislymphoma syndrome. Medical oncology 2007, 24, 469-471.

26. Falchero, L.; Nesme, P.; Perol, M.; Guerin, J.C. [spontaneous resolution of multiorgan sarcoidosis associated with malignant lymphoma]. Revue des maladies respiratoires 1998, 15, 287-289.

27. Tjan-Heijnen, V.C.; Vlasveld, L.T.; Pernet, F.P.; Pauwels, P.; De Mulder, P.H. Coincidence of seminoma and sarcoidosis: A myth or fact? Annals of oncology : official journal of the European Society for Medical Oncology / ESMO 1998, 9, 321-325. 
28. Morand, J.J.; Paris, J.F.; Gisserot, O.; Terrier, J.P.; Carsuzaa, F.; Carli, P. [pseudo-sarcoidotic lymphoma and nephrotic syndrome in a hepatitis c-carrying female patient]. La Presse medicale 1998, 27, 668.

29. Sorrells, T.; Pratt, L.; Newton, J.; Graham, S.; Ryan, M. Spontaneous regression of granulomatous mycosis fungoides in an hiv positive patient. $J$ Am Acad Dermatol 1997, 37, 876-880.

30. Jager, J.; Andriessen, M.P.; van Ingen, J. Bone lesions mimicking disseminated malignancy after remission of thoracic sarcoidosis. The Netherlands journal of medicine 1990, 36, 204-206.

31. Prevost, J.N.; Marin, I.; Othman, H.; Chretien, J. [recurrence of sarcoidosis stage i after recovery]. La Presse medicale 1986, 15, 761.

32. de la Figuera, M.; Biosca, M.; Garcia-Bragado, F.; Villar, M.; Magrina, C. Spontaneous regression of bilateral hilar lymphadenopathy in renal cell carcinoma. European journal of respiratory diseases 1985, 67, 133-135.

33. Goljan-Geremek, A.; Puscinska, E.; Bednarek, M.; Nowinski, A.; Kaminski, D.; Ptak, J.; Bestry, I.; Langfort, R.; Staszewska, M.; Gorecka, D. Fatal clinical outcome in a patient with sarcoidosislymphoma syndrome. Pneumonologia i alergologia polska 2013, 81, 542-549.

34. Hunt, D.P.; Muse, V.V.; Ly, A. Case records of the massachusetts general hospital. Case 4-2014. A 39-year-old man with night sweats and abdominal pain. The New England journal of medicine 2014, 370, 467-473.

35. Macri, A.; Constantin, A.; Cordos, I.; Stoica, R. [coexistence of mediastinal adenopathies of different etiologies -- case report]. Pneumologia (Bucharest, Romania) 2013, 62, 114-121.

36. Tanizawa, K.; Tanaka, E.; Hashimoto, S.; Noma, S.; Kobashi, Y.; Okumura, K.; Shindo, T.; Taguchi, Y. Paradoxical development of a sarcoid-like reaction during successful chemotherapy for seminoma. Internal medicine 2010, 49, 1423-1426.

37. Grutters, J.C.; van den Bosch, J.M. Corticosteroid treatment in sarcoidosis. Eur Respir J 2006, 28, 627-636.

38. Von Helden, R. Healthy in seven days - success through vitamin d treatment. 1 ed.; Hygeia Publishing: Dresden, 2014.

39. Kirsten, D., Magnusson, Helgo. Sarcoidose up-date 2000. Interpneu: 2000.

40. Muller-Quernheim, J. Sarcoidosis: Immunopathogenetic concepts and their clinical application. Eur Respir J 1998, 12, 716-738.

41. Rose, C.S.; Martyny, J.W.; Newman, L.S.; Milton, D.K.; King, T.E., Jr.; Beebe, J.L.; McCammon, J.B.; Hoffman, R.E.; Kreiss, K. "Lifeguard lung": Endemic granulomatous pneumonitis in an indoor swimming pool. American journal of public health 1998, 88, 17951800 .

42. Saidha, S.; Sotirchos, E.S.; Eckstein, C. Etiology of sarcoidosis: Does infection play a role? The Yale journal of biology and medicine 2012, 85, 133-141.

43. Rafnsson, V.; Ingimarsson, O.; Hjalmarsson, I.; Gunnarsdottir, H. Association between exposure to crystalline silica and risk of sarcoidosis. Occupational and environmental medicine 1998, 55, 657-660.

44. De Vuyst, P.; Dumortier, P.; Moulin, E.; Yourassowsky, N.; Yernault, J.C. Diagnostic value of asbestos bodies in bronchoalveolar lavage fluid. The American review of respiratory disease 1987, 136, 1219-1224. 
45. Newman, L.S. Metals that cause sarcoidosis. Seminars in respiratory infections 1998, 13, 212220.

46. Redline, S.; Barna, B.P.; Tomashefski, J.F., Jr.; Abraham, J.L. Granulomatous disease associated with pulmonary deposition of titanium. British journal of industrial medicine 1986, 43, 652-656.

47. Skelton, H.G., 3rd; Smith, K.J.; Johnson, F.B.; Cooper, C.R.; Tyler, W.F.; Lupton, G.P. Zirconium granuloma resulting from an aluminum zirconium complex: A previously unrecognized agent in the development of hypersensitivity granulomas. $J$ Am Acad Dermatol 1993, 28, 874-876.

48. Newman, L.S.; Rose, C.S.; Bresnitz, E.A.; Rossman, M.D.; Barnard, J.; Frederick, M.; Terrin, M.L.; Weinberger, S.E.; Moller, D.R.; McLennan, G., et al. A case control etiologic study of sarcoidosis: Environmental and occupational risk factors. Am J Respir Crit Care Med 2004, 170, 1324-1330.

49. Safianowska, A.; Grubek-Jaworska, H.; Droszcz, P.; Rybus, L.; Dabrowski, A.; Zwolska, Z.; Matysiak, W.; Chazan, R. [levels of cea, antibodies against mycobacterial antigens and ace activity in serum and in balf in patients with sarcoidosis, tuberculosis and lung cancer-preliminary results]. Pneumonologia i alergologia polska 2001, 69, 5-13.

50. Dabrowska, M.; Grubek-Jaworska, H.; Domagala-Kulawik, J.; Bartoszewicz, Z.; Kondracka, A.; Krenke, R.; Nejman, P.; Chazan, R. [diagnostic usefulness of selected tumor markers (ca125, cea, cyfra 21-1) in bronchoalveolar lavage fluid in patients with non-small cell lung cancer]. Polskie Archiwum Medycyny Wewnetrznej 2004, 111, 659-665.

51. Alexandrescu, D.T.; Kauffman, C.L.; Ichim, T.E.; Riordan, N.H.; Kabigting, F.; Dasanu, C.A. Cutaneous sarcoidosis and malignancy: An association between sarcoidosis with skin manifestations and systemic neoplasia. Dermatology online journal 2011, 17, 2.

52. Brincker, H. Sarcoidosis and malignancy. Chest 1995, 108, 1472-1474.

53. Caras, W.E.; Dillard, T.; Baker, T.; Pluss, J. Coexistence of sarcoidosis and malignancy. Southern medical journal 2003, 96, 918-922.

54. Cohen, P.R.; Kurzrock, R. Sarcoidosis and malignancy. Clin Dermatol 2007, 25, 326-333.

55. Bonifazi, M.; Bravi, F.; Gasparini, S.; La Vecchia, C.; Gabrielli, A.; Wells, A.U.; Renzoni, E.A. Sarcoidosis and cancer risk: Systematic review and meta-analysis of observational studies. Chest 2015, 147, 778-791.

56. Seersholm, N.; Vestbo, J.; Viskum, K. Risk of malignant neoplasms in patients with pulmonary sarcoidosis. Thorax 1997, 52, 892-894.

57. Ungprasert, P.; Srivali, N.; Wijarnpreecha, K.; Thongprayoon, C.; Cheungpasitporn, W.; Knight, E.L. Is the incidence of malignancy increased in patients with sarcoidosis? A systematic review and meta-analysis. Respirology 2014, 19, 993-998.

58. Yukawa, Y.; Kato, F. Isolated spinal cord sarcoidosis mimicking an intramedullary tumor. Journal of spinal disorders 1999, 12, 530-533.

59. Woolf, R.; Toms, L.; Mann, B. Systemic sarcoidosis mimicking advanced testicular cancer. $J R$ Soc Med 2010, 103, 251-253.

60. Wilson, J.D.; Castillo, M.; Van Tassel, P. Mri features of intracranial sarcoidosis mimicking meningiomas. Clinical imaging 1994, 18, 184-188. 
61. Weiss, I.A.; Limaye, A.; Tchertkoff, V.; Brener, J.L. Sarcoidosis of the thyroid clinically mimicking malignancy. New York state journal of medicine 1989, 89, 578-580.

62. Weil, R.J. Meningeal neurosarcoidosis mimicking convexity meningioma. Case illustration. Journal of neurosurgery 2001, 94, 1013.

63. Vaz, F.M.; Samuel, D. Postcricoid sarcoid mimicking a malignancy: A lesson to remember. Otolaryngology-head and neck surgery : official journal of American Academy of Otolaryngology-Head and Neck Surgery 2000, 123, 150.

64. Valencia, M.P.; Deaver, P.M.; Mammarappallil, M.C. Sarcoidosis of the thoracic and lumbar vertebrae, mimicking metastasis or multifocal osteomyelitis by mri: Case report. Clinical imaging 2009, 33, 478-481.

65. Uruha, A.; Koide, R.; Taniguchi, M. Unusual presentation of sarcoidosis: Solitary intracranial mass lesion mimicking a glioma. Journal of neuroimaging : official journal of the American Society of Neuroimaging 2011, 21, e180-182.

66. Umezu, H.; Chida, M.; Inoue, T.; Araki, O.; Tamura, M.; Tatewaki, M.; Fukushima, Y.; Honma, K. Sarcoidosis development during induction chemotherapy for lung cancer mimicked progressive disease. General thoracic and cardiovascular surgery 2010, 58, 434-437.

67. Tsao, C.Y.; Lo, W.D.; Rusin, J.A.; Henwood, M.J.; Boue, D.R. Isolated neurosarcoidosis presenting as headache and multiple brain and spinal cord lesions mimicking central nervous system metastases. Brain \& development 2007, 29, 514-518.

68. Tolaney, S.M.; Colson, Y.L.; Gill, R.R.; Schulte, S.; Duggan, M.M.; Shulman, L.N.; Winer, E.P. Sarcoidosis mimicking metastatic breast cancer. Clinical breast cancer 2007, 7, 804-810.

69. Talmi, D.; Smith, S.; Mulligan, M.E. Central skeletal sarcoidosis mimicking metastatic disease. Skeletal radiology 2008, 37, 757-761.

70. Talamonti, G.; Ligarotti, G.K.; Bramerio, M.; Imbesi, F. Unusual behaviour of a pineal germinoma mimicking neurosarcoidosis and metastasising along the endoscopic route. BMJ case reports 2013, 2013.

71. Takanami, K.; Kaneta, T.; Yamada, T.; Kinomura, S.; Yamada, S.; Fukuda, H.; Takahashi, S. Fdg pet for esophageal cancer complicated by sarcoidosis mimicking mediastinal and hilar lymph node metastases: Two case reports. Clinical nuclear medicine 2008, 33, 258-261.

72. Suzuki, K.; Morise, Z.; Furuta, S.; Tanahashi, Y.; Takeura, C.; Kagawa, T.; Ikeda, M.; Sugioka, A. Hepatic sarcoidosis mimicking hilar cholangiocarcinoma: Case report and review of the literature. Case reports in gastroenterology 2011, 5, 152-158.

73. SultanAli, I.; Zaman, M.; Yende, S. Sarcoidosis mimicking disseminated testicular cancer. Southern medical journal 2005, 98, 935-936.

74. Su, C.T.; Chen, L.K.; Tsai, Y.F.; Kuo, C.J.; Lu, C.L.; Chen, H.Y. Disseminated cryptococcosis with pulmonary and marrow involvement mimicking radiological features of malignancy. Journal of the Chinese Medical Association : JCMA 2004, 67, 89-92.

75. Strickland-Marmol, L.B.; Fessler, R.G.; Rojiani, A.M. Necrotizing sarcoid granulomatosis mimicking an intracranial neoplasm: Clinicopathologic features and review of the literature. Modern pathology : an official journal of the United States and Canadian Academy of Pathology, Inc 2000, 13, 909-913. 
76. Stokkel, M.P.; van der Hiel, B.; Olmos, R.V.; Hoefnagel, K. Fluorodeoxyglucose pet/ct in subcutaneous sarcoidosis mimicking cutaneous lymphoma. European journal of nuclear medicine and molecular imaging 2012, 39, 919-920.

77. Soyer, P.; Gottlieb, L.; Bluemke, D.A.; Fishman, E. Sarcoidosis of the pancreas mimicking pancreatic cancer: Ct features. European journal of radiology 1994, 19, 32-33.

78. Sickles, E.A.; Sklansky, B.D.; Wiernik, P.H. Benign intrathoracic lesions mimicking recurrent cancer. Jama 1973, 225, 156-158.

79. Shiraishi, Y.; Kimura, A.; Seichi, A.; Inoue, H.; Yamamuro, K.; Kojima, M.; Hoshino, Y. Multifocal extramedullary spinal sarcoid lesions mimicking leptomeningeal metastasis. Journal of orthopaedic science : official journal of the Japanese Orthopaedic Association 2013, 18, 343-346.

80. Sahin, H.; Ceylan, N.; Bayraktaroglu, S.; Tasbakan, S.; Veral, A.; Savas, R. Necrotizing sarcoid granulomatosis mimicking lung malignancy: Mdct, pet-ct and pathologic findings. Iranian journal of radiology : a quarterly journal published by the Iranian Radiological Society 2012, 9 , $37-41$.

81. Sagalow, B.R.; Miller, C.L.; Wechsler, R.J. Pancreatic sarcoidosis mimicking pancreatic cancer. Journal of clinical ultrasound: JCU 1988, 16, 131-134.

82. Rodriguez, F.; Link, M.J.; Driscoll, C.L.; Giannini, C. Neurosarcoidosis mimicking meningioma. Archives of neurology 2005, 62, 148-149.

83. Rice, C.M.; Beric, V.; Love, S.; Scolding, N.J. Neurological picture. Vertebral sarcoidosis mimicking metastases. Journal of neurology, neurosurgery, and psychiatry 2011, 82, 188.

84. Rawlings, D.J.; Bernstein, B.; Rowland, J.M.; Shaham, B.; Szer, I.S. Prolonged course of illness in a child with malignant lymphoma mimicking sarcoidosis. The Journal of rheumatology $\mathbf{1 9 9 3 ,}$ 20, 1583-1587.

85. Ramanathan, R.S.; Malhotra, K.; Scott, T. Teaching neuroimages: Diffuse cerebral neurosarcoidosis mimicking gliomatosis cerebri. Neurology 2013, 81, e46.

86. Quinones-Hinojosa, A.; Chang, E.F.; Khan, S.A.; McDermott, M.W. Isolated trigeminal nerve sarcoid granuloma mimicking trigeminal schwannoma: Case report. Neurosurgery 2003, 52, 700705 discussion 704-705.

87. Pungpapong, S.; Steers, J.L.; Wallace, M.B.; Krishna, M.; Keaveny, A.P. Hepatobiliary sarcoidosis mimicking klatskin's cholangiocarcinoma. Gastrointestinal endoscopy 2006, 64, 124125.

88. Powers, W.J.; Miller, E.M. Sarcoidosis mimicking glioma: Case report and review of intracranial sarcoid mass lesions. Neurology 1981, 31, 907-910.

89. Powell, J.L.; Cunill, E.S.; Gajewski, W.H.; Novotny, D.B. Sarcoidosis mimicking recurrent endometrial cancer. Gynecologic oncology 2005, 99, 770-773.

90. Pollock, J.M.; Greiner, F.G.; Crowder, J.B.; Crowder, J.W.; Quindlen, E. Neurosarcoidosis mimicking a malignant optic glioma. Journal of neuro-ophthalmology : the official journal of the North American Neuro-Ophthalmology Society 2008, 28, 214-216.

91. Piattelli, A.; Favia, G.F.; Di Alberti, L. Oral ulceration as a presenting sign of unknown sarcoidosis mimicking a tumour: Report of 2 cases. Oral oncology 1998, 34, 427-430. 
92. Paydas, S.; Disel, U.; Yavuz, S.; Ergin, M. Granulomatous orchitis mimicking hodgkin's lymphoma relapse. The hematology journal : the official journal of the European Haematology Association / EHA 2003, 4, 370-371.

93. Packer, C.D.; Mileti, L.M. Vertebral sarcoidosis mimicking lytic osseous metastases: Development 16 years after apparent resolution of thoracic sarcoidosis. Journal of clinical rheumatology : practical reports on rheumatic \& musculoskeletal diseases 2005, 11, 105-108.

94. Osenbach, R.K.; Blumenkopf, B.; Ramirez, H., Jr.; Gutierrez, J. Meningeal neurosarcoidosis mimicking convexity en-plaque meningioma. Surgical neurology 1986, 26, 387-390.

95. Oketani, M.; Tsubouchi, H.; Hori, T.; Sakamoto, K.; Kawakami, S.; Yoshimitsu, N.; Matsuo, T.; Hirono, S.; Shimoide, Y.; Miura, T., et al. Sarcoidosis with tumorous hepatic and bone lesions mimicking disseminated malignancy: A case report. Gastroenterologia Japonica 1992, 27, 414417.

96. Ohana, G.; Melki, Y.; Rosenblat, Y.; Kravarusic, D.; Weil, R. Pancreatic sarcoidosis mimicking a malignant tumour. The European journal of surgery = Acta chirurgica 2002, 168, 513-515.

97. Nowak, D.A.; Gumprecht, H.; Widenka, D.C.; Stolzle, A.; Lumenta, C.B. Solitary sarcoid granulomatosis mimicking meningioma. Journal of neurosurgery 2000, 93, 897.

98. North, J.; Mully, T. Alpha-interferon induced sarcoidosis mimicking metastatic melanoma. Journal of cutaneous pathology 2011, 38, 585-589.

99. Nehls, O.; Hass, H.G.; Weber, P.; Dette, S.; Lauer, U.M.; Schlemmer, H.P.; Oehlert, M.; Gregor, M.; Klump, B. Sarcoidosis mimicking cholangiocarcinoma. Endoscopy 2006, 38 Suppl 2, E65-66.

100. Naraynsingh, V.; Hariharan, S.; Dan, D.; Harnarayan, P.; Teelucksingh, S. Conservative management for idiopathic granulomatous mastitis mimicking carcinoma: Case reports and literature review. Breast disease 2010, 31, 57-60.

101. Mosnier, E.; Siles, P.; Ebbo, M.; Bernit, E.; Veit, V.; Tintignac, A.; Chagnaud, C.; Harle, J.R.; Schleinitz, N. Clinical images: Bone sarcoidosis mimicking multiple metastases. Arthritis and rheumatism 2011, 63, 1542.

102. Mingins, C.; Williams, M.R.; Cox, N.H. Subcutaneous sarcoidosis mimicking breast carcinoma. Br J Dermatol 2002, 146, 924-925.

103. Mayne, A.I.; Ahmad, J.; Loughrey, M.; Taylor, M.A. Sarcoidosis of the pancreas mimicking adenocarcinoma. BMJ case reports 2013, 2013.

104. Mapelli, P.; Mangili, G.; Picchio, M.; Rabaiotti, E.; Gianolli, L.; Messa, C.; Candiani, M. Sarcoidosis mimicking metastatic gynaecological malignancies: A diagnostic and therapeutic challenge? Revista espanola de medicina nuclear e imagen molecular 2013, 32, 314-317.

105. Majori, M.; Anghinolfi, M.; Scarascia, A.; Gnetti, L.; Pavarani, A.; Casalini, A. Pulmonary sarcoidosis mimicking multiple pulmonary metastases. Monaldi archives for chest disease = Archivio Monaldi per le malattie del torace / Fondazione clinica del lavoro, IRCCS [and] Istituto di clinica tisiologica e malattie apparato respiratorio, Universita di Napoli, Secondo ateneo 2012, 77, 38-39.

106. MacGregor, G. Giant-cell arteritis mimicking carcinoma of the breast. British medical journal (Clinical research ed.) 1981, 283, 236. 
107. Ludwig, V.; Fordice, S.; Lamar, R.; Martin, W.H.; Delbeke, D. Unsuspected skeletal sarcoidosis mimicking metastatic disease on fdg positron emission tomography and bone scintigraphy. Clinical nuclear medicine 2003, 28, 176-179.

108. Looijen, R.; Hoekstra, H.J.; Sleijfer, D.T.; Postmus, P.; Oosterhuis, J.W.; de Boer, W.J.; Schraffordt Koops, H. Sarcoid reaction mimicking intrathoracic dissemination of testicular cancer. Cancer 1990, 66, 2221-2223.

109. Lipper, M.H.; Goldstein, J.M. Neurosarcoidosis mimicking a cerebellopontine angle meningioma. AJR. American journal of roentgenology 1998, 171, 275-276.

110. Li, W.; Holdeman, K.; Laurini, J.A.; Bierman, P.J.; Vose, J.M.; Bociek, R.G.; Armitage, J.O. Sarcoidosis mimicking recurrent lymphoma. American journal of hematology 2012, 87, 711-712.

111. Lee, M.; Epstein, F.J.; Rezai, A.R.; Zagzag, D. Nonneoplastic intramedullary spinal cord lesions mimicking tumors. Neurosurgery 1998, 43, 788-794; discussion 794-785.

112. Kolilekas, L.; Triantafillidou, C.; Manali, E.; Rontogianni, D.; Chatziioannou, S.; Papiris, S. The many faces of sarcoidosis: Asymptomatic muscle mass mimicking giant-cell tumor. Rheumatol Int 2009, 29, 1389-1390.

113. Kok, T.C.; Haasjes, J.G.; Splinter, T.A.; ten Kate, F.J. Sarcoid-like lymphadenopathy mimicking metastatic testicular cancer. Cancer 1991, 68, 1845-1847.

114. Kim, Y.B.; Chung, Y.G.; Kim, S.J.; Kim, S.J.; Ahn, H.S.; Joo, H.J.; Kim, S.I. Extensive systemic sarcoidosis with testicular involvement mimicking metastatic testicular cancer. Korean journal of urology 2011, 52, 295-297.

115. Kim, M.H.; Lee, K.; Kim, K.U.; Park, H.K.; Lee, M.K.; Suh, D.S. Sarcoidosis mimicking cancer metastasis following chemotherapy for ovarian cancer. Cancer research and treatment : official journal of Korean Cancer Association 2013, 45, 354-358.

116. Khiar, A.; Duet, M.; Ammari, S.; Brouland, J.P.; Liote, F.; Paycha, F. Disseminated bone involvement in systemic sarcoidosis mimicking bone metastases. A multimodality imaging approach. Joint, bone, spine : revue du rhumatisme 2011, 78, 216-217.

117. Kay, J.M. Correspondence re: Strictland-marmol lb, fessler rg, rojiani am. Necrotizing sarcoid granulomatosis mimicking an intracranial neoplasm: Clinicopathologic features and review of the literature. Mod pathol 2000;13:909-3. Modern pathology : an official journal of the United States and Canadian Academy of Pathology, Inc 2001, 14, 533.

118. Karmaniolas, K.; Liatis, S.; Dalamaga, M.; Mourouti, G.; Digeni, A.; Migdalis, I. A case of ovarian sarcoidosis mimicking malignancy. European journal of gynaecological oncology 2005, 26, 231-232.

119. Jung, G.; Brill, N.; Poll, L.W.; Koch, J.A.; Wettstein, M. Mri of hepatic sarcoidosis: Large confluent lesions mimicking malignancy. AJR. American journal of roentgenology 2004, 183, 171-173.

120. Johnson, M.D.; Powell, S.Z.; Boyer, P.J.; Weil, R.J.; Moots, P.L. Dural lesions mimicking meningiomas. Human pathology 2002, 33, 1211-1226.

121. Jackson, R.J.; Goodman, J.C.; Huston, D.P.; Harper, R.L. Parafalcine and bilateral convexity neurosarcoidosis mimicking meningioma: Case report and review of the literature. Neurosurgery 1998, 42, 635-638. 
122. Hollister, D., Jr.; Lee, M.S.; Eisen, R.N.; Fey, C.; Portlock, C.S. Variable problems in lymphomas: Case 2. Sarcoidosis mimicking progressive lymphoma. Journal of clinical oncology : official journal of the American Society of Clinical Oncology 2005, 23, 8113-8116.

123. Herrero Fernandez, B.; Fernandez Perez, E.; Rodriguez Fuertes, S.J.; Bahamonde Carrasco, A.; Moran Blanco, A.; Munoz Rodriguez, M. [neurosarcoidosis mimicking cerebral tumor]. Anales de medicina interna 1997, 14, 139-141.

124. Henrichs, M.P.; Streitburger, A.; Gosheger, G.; Surke, C.; Dierkes, C.; Hardes, J. Scar sarcoidosis on a finger mimicking a rapidly growing soft tissue tumour: A case report. BMC research notes 2012, 5, 545.

125. Gusakova, I.; Lavrenkov, K.; Ariad, S.; Mermershtain, W. Pulmonary sarcoidosis mimicking metastases in breast cancer patients. Onkologie 2007, 30, 327-328.

126. Grubstein, A.; Cohen, M.; Steinmetz, A.; Cohen, D. Siliconomas mimicking cancer. Clinical imaging 2011, 35, 228-231.

127. Gallimore, A.P.; George, C.D.; Lampert, I.A. Subcutaneous sarcoidosis mimicking carcinoma of the breast. Postgraduate medical journal 1990, 66, 677-678.

128. Fujimoto, H.; Ikeda, M.; Shimofusa, R.; Terauchi, M.; Eguchi, M. Sarcoidosis breaching the fascia and mimicking a sarcoma. Skeletal radiology 2002, 31, 706-708.

129. Fuchs, F.; Le Tohic, A.; Raynal, P.; Guillot, E.; Chis, C.; Meckenstock, R.; Panel, P. [ovarian and peritoneal sarcoidosis mimicking an ovarian cancer]. Gynecologie, obstetrique \& fertilite $\mathbf{2 0 0 7}$, $35,41-44$.

130. Fong, Z.V.; Wong, J.; Maley, W.R.; Sandorfi, N.; Winter, J.M.; Koniaris, L.G.; Sauter, P.K.; Yeo, C.J.; Lavu, H. Sarcoid-reaction mimicking metastatic malignant hepatopancreatobiliary tumors: Report of two cases and review of the literature. Journal of gastrointestinal surgery : official journal of the Society for Surgery of the Alimentary Tract 2012, 16, 1245-1250.

131. Fitch, P.S.; Smith, M.E.; Davies, M.G.; Prentice, A.G. A case of lymphomatoid granulomatosis mimicking sarcoidosis. Respiratory medicine 1998, 92, 966-968.

132. Fazzi, P.; Solfanelli, S.; Morelli, G.; Orsitto, E.; Pieri, L.; Petrini, M.; Giuntini, C. Sarcoidosis: Single bulky mesenteric lymph node mimicking a lymphoma. Sarcoidosis 1995, 12, 75-77.

133. Esnakula, A.K.; Coleman, P.; Ahaghotu, C.A.; Naab, T.J. Scrotal mass and unilateral lung masses with pleural effusion mimicking metastatic testicular malignancy: An unusual presentation of sarcoidosis. BMJ case reports 2013, 2013.

134. Curti, A.; Rampini, C.; Gallazzi, M.; Tramontana, F.; Garbagna, G.P. [isolated muscular sarcoidosis mimicking a tumoral lesion]. Reumatismo 2004, 56, 57-60.

135. Connellan, S.J.; Perceval, P.E.; Wilson, R.S. Sarcoidosis mimicking malignancy. British journal of diseases of the chest 1978, 72, 343-344.

136. Bush, E.; Lamonica, D.; O'Connor, T. Sarcoidosis mimicking metastatic breast cancer. The breast journal 2011, 17, 533-535.

137. Bose, B. Extramedullary sarcoid lesion mimicking intraspinal tumor. The spine journal : official journal of the North American Spine Society 2002, 2, 381-385.

138. Bodo, M.; Dobrossy, L.; Sugar, J. Boeck's sarcoidosis of the breast: Cytologic findings with aspiration biopsy cytology. A case clinically mimicking carcinoma. Acta cytologica 1978, 22, 1-2. 
139. Bodie, B.F.; Kheir, S.M.; Omura, E.F. Calvarial sarcoid mimicking metastatic disease. J Am Acad Dermatol 1980, 3, 401-405.

140. Beros, V.; Houra, K.; Rotim, K.; Kovac, D.; Cupic, H. Thoracic intramedullary sarcoidosis mimicking an intramedullary tumor. Collegium antropologicum 2008, 32, 645-647.

141. Bauones, S.; Le Corroller, T.; Durieux, O.; Guenoun, D.; Del Grande, J.; Pirro, N.; Champsaur, P. Splenic sarcoidosis mimicking neoplastic disease. Journal of clinical ultrasound : JCU 2014, 42, 38-41.

142. Barazi, S.; Bodi, I.; Thomas, N. Sarcoidosis presenting as an isolated extradural thoracolumbar lesion mimicking tumour. British journal of neurosurgery 2008, 22, 690-691.

143. Arana Yi, C.; McCue, P.; Rosen, M.; Machtay, M.; Axelrod, R.; Morris, G.J. Sarcoidosis mimicking metastatic bone disease in head and neck cancer. Seminars in oncology 2013, 40, 529534.

144. Akdogan, M.; Ulas, M.; Kayhan, B.; Orug, T.; Aydog, G. Gastrointestinal sarcoidosis mimicking colonic cancer. The Turkish journal of gastroenterology : the official journal of Turkish Society of Gastroenterology 2008, 19, 136-138.

145. Abrey, L.E.; Rosenblum, M.K.; DeAngelis, L.M. Sarcoidosis of the cauda equina mimicking leptomeningeal malignancy. Journal of neuro-oncology 1998, 39, 261-265.

146. Bansal, A.S.; Bruce, J.; Hogan, P.G.; Allen, R.K. An assessment of peripheral immunity in patients with sarcoidosis using measurements of serum vitamin $\mathrm{d} 3$, cytokines and soluble cd23. Clinical and experimental immunology 1997, 110, 92-97.

147. Garland, C.F.; Gorham, E.D.; Mohr, S.B.; Grant, W.B.; Giovannucci, E.L.; Lipkin, M.; Newmark, H.; Holick, M.F.; Garland, F.C. Vitamin d and prevention of breast cancer: Pooled analysis. $J$ Steroid Biochem Mol Biol 2007, 103, 708-711.

148. Gorham, E.D.; Garland, C.F.; Garland, F.C.; Grant, W.B.; Mohr, S.B.; Lipkin, M.; Newmark, H.L.; Giovannucci, E.; Wei, M.; Holick, M.F. Vitamin d and prevention of colorectal cancer. $J$ Steroid Biochem Mol Biol 2005, 97, 179-194.

149. Adams, J.S.; Singer, F.R.; Gacad, M.A.; Sharma, O.P.; Hayes, M.J.; Vouros, P.; Holick, M.F. Isolation and structural identification of 1,25-dihydroxyvitamin $\mathrm{d} 3$ produced by cultured alveolar macrophages in sarcoidosis. J Clin Endocrinol Metab 1985, 60, 960-966.

150. Adams, J.S.; Gacad, M.A.; Singer, F.R.; Sharma, O.P. Production of 1,25-dihydroxyvitamin d3 by pulmonary alveolar macrophages from patients with sarcoidosis. Ann NY Acad Sci 1986, 465, 587-594.

151. Monkawa, T.; Yoshida, T.; Hayashi, M.; Saruta, T. Identification of 25-hydroxyvitamin d3 1alpha-hydroxylase gene expression in macrophages. Kidney Int 2000, 58, 559-568.

152. Berlin, J.L.; Shantha, G.P.; Yeager, H.; Thomas-Hemak, L. Serum vitamin d levels may not reflect tissue-level vitamin d in sarcoidosis. BMJ case reports 2014, 2014.

153. Overbergh, L.; Stoffels, K.; Waer, M.; Verstuyf, A.; Bouillon, R.; Mathieu, C. Immune regulation of 25-hydroxyvitamin d-1alpha-hydroxylase in human monocytic thp1 cells: Mechanisms of interferon-gamma-mediated induction. J Clin Endocrinol Metab 2006, 91, 3566-3574.

154. Fleet, J.C. Molecular actions of vitamin d contributing to cancer prevention. Mol Aspects Med 2008, 29, 388-396. 
155. Gregory, K.J.; Zhao, B.; Bielenberg, D.R.; Dridi, S.; Wu, J.; Jiang, W.; Huang, B.; PirieShepherd, S.; Fannon, M. Vitamin d binding protein-macrophage activating factor directly inhibits proliferation, migration, and upar expression of prostate cancer cells. PLoS One 2010, 5, e13428.

156.Zimmerman, J.; Holick, M.F.; Silver, J. Normocalcemia in a hypoparathyroid patient with sarcoidosis: Evidence for parathyroid-hormone-independent synthesis of 1,25 dihydroxyvitamin d. Annals of internal medicine 1983, 98, 338 .

157. Grant WB, M.M. Role of ultraviolet-b irradiance and vitamin d in reducing risk of cancer. Nova Science Publishers, Inc. NY. 2014, 2014.

158. Moukayed, M.; Grant, W.B. Molecular link between vitamin d and cancer prevention. Nutrients 2013, 5, 3993-4021.

159. Wang, Y.; Zhu, J.; DeLuca, H.F. Where is the vitamin d receptor? Archives of biochemistry and biophysics 2012, 523, 123-133.

160. Matthews, D.; LaPorta, E.; Zinser, G.M.; Narvaez, C.J.; Welsh, J. Genomic vitamin d signaling in breast cancer: Insights from animal models and human cells. J Steroid Biochem Mol Biol 2010, 121, 362-367.

161. Welsh, J. Targets of vitamin d receptor signaling in the mammary gland. Journal of bone and mineral research : the official journal of the American Society for Bone and Mineral Research 2007, 22 Suppl 2, V86-90.

162. Steinfort, D.P.; Tsui, A.; Grieve, J.; Hibbs, M.L.; Anderson, G.P.; Irving, L.B. Sarcoidal reactions in regional lymph nodes of patients with early stage non-small cell lung cancer predict improved disease-free survival: A pilot case-control study. Human pathology 2012, 43, 333-338.

163. Bolland, M.J.; Wilsher, M.L.; Grey, A.; Horne, A.M.; Fenwick, S.; Gamble, G.D.; Reid, I.R. Randomised controlled trial of vitamin d supplementation in sarcoidosis. BMJ open 2013, 3, e003562.

164. Kamphuis, L.S.; Bonte-Mineur, F.; van Laar, J.A.; van Hagen, P.M.; van Daele, P.L. Calcium and vitamin d in sarcoidosis: Is supplementation safe? Journal of bone and mineral research : the official journal of the American Society for Bone and Mineral Research 2014, 29, 2498-2503.

165. Von Helden, R. Two cases of chronic sarcoidosis came in a prompt remission under a treatment with vitamin d In Poster-Presentation Auditory, Ed. Kongress Vitamin D Update 2013: Berlin, Charite, Vitamin D Update 2013, 2013.

166. Zittermann, A.; von Helden, R.; Grant, W.; Kipshoven, C.; Ringe, J.D. An estimate of the survival benefit of improving vitamin $\mathrm{d}$ status in the adult german population. Dermato-endocrinology 2009, 1, 300-306.

167. Von Helden, R. Hypothesis: Sarcoidosis is a useful defensive response to malignant cells. Treatment with vitamin d supports this defense process and can induce a spontaneous remission. Auditory, Ed. Kongress Vitamin D Update 2013: Berlin, Charite, Vitamin D Update 2013, 2013. 